\title{
ADC
}

\section{Neonatal total IgE and respiratory tract infections in children with intrauterine smoke exposure}

Jopje Ruskamp, Henriette Smit, Maroeska Rovers, et al.

Arch Dis Child 2010 95: 427-431 originally published online April 19, 2010 doi: 10.1136/adc.2009.162685

Updated information and services can be found at:

http://adc.bmj.com/content/95/6/427.full.html

\section{These include:}

References This article cites 30 articles, 15 of which can be accessed free at: http://adc.bmj.com/content/95/6/427.full.html\#ref-list-1

Email alerting Receive free email alerts when new articles cite this article. Sign up in the service box at the top right corner of the online article.

Notes

To order reprints of this article go to:

http://adc.bmj.com/cgi/reprintform

To subscribe to Archives of Disease in Childhood go to:

http://adc.bmj.com/subscriptions 


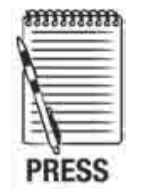

RELEASE

\title{
Neonatal total IgE and respiratory tract infections in children with intrauterine smoke exposure
}

\author{
Jopje Ruskamp, ${ }^{1}$ Henriette Smit, ${ }^{2}$ Maroeska Rovers, ${ }^{3}$ Maarten Hoekstra, ${ }^{1}$ \\ Anne Schilder, ${ }^{4}$ Bert Brunekreef, ${ }^{3,5}$ Alet Wijga, ${ }^{2}$ Marjan Kerkhof, ${ }^{6}$ Johan de Jongste, ${ }^{7}$ \\ Elisabeth Sanders ${ }^{8}$
}

'Department of Paediatrics, Wilhelmina Children's

Hospital, University Medical Centre Utrecht, Utrecht, the

Netherlands

${ }^{2}$ Centre for Prevention and Health Services Research,

National Institute of Public

Health and the Environment

Bilthoven, the Netherlands

${ }^{3}$ Julius Centre of Health

Sciences and Primary

Care, University Medical

Centre Utrecht, Utrecht, the

Netherlands

${ }^{4}$ Department of Paediatric

orhinolaryngology, Wilhelmina

Children's Hospital, University

Medical Centre Utrecht,

Utrecht, the Netherlands

5 Institute for Risk Assessment

Sciences, University of

Utrecht, Utrecht, the

Netherlands

${ }^{6}$ Department of Epidemiology,

University Medical Centre

Groningen, Groningen, the

Netherlands

${ }^{7}$ Department of Paediatrics,

Sophia Children's Hospital,

Erasmus University,

Rotterdam, the Netherlands

${ }^{8}$ Department of Paediatric

Immunology, Wilhelmina

Children's Hospital, University

Medical Centre Utrecht,

Utrecht, the Netherlands

\section{Correspondence to}

Jopje Ruskamp, Department of Paediatrics, Wilhelmina Children's Hospital, University Medical Centre Utrecht, PO Box 85090, 3508 AB Utrecht, the Netherlands; j.ruskamp@umcutrecht.nl

Accepted 22 December 2009

\begin{abstract}
Background Exposure to environmental tobacco smoke (ETS) is known to increase the risk of respiratory tract infections (RTI). Some children, however, may be more susceptible to the harmful effects of ETS than others. We examined whether early atopic status (defined by elevated neonatal total lgE (tlgE) or symptoms of atopic dermatitis) modified the association between ETS exposure and RTI.
\end{abstract}

Methods The data of 2863 children from the Prevention and Incidence of Asthma and Mite Allergy birth cohort were collected to the age of 4 years. Neonatal tlgE was collected from a subset of 914 children, and clinical information by yearly parental questionnaires. The effect of pre- and/or postnatal ETS exposure, early atopic status and interaction between these factors was studied for various RTI.

Results Children with elevated tlgE or atopic dermatitis and prenatal ETS exposure have a strongly increased risk of frequent RTI (aOR 6.18 (95\% Cl 1.45 to 26.34 ) and 5.69 (2.01 to 16.04), respectively; interaction $p=0.006$ and $p=0.14$, respectively) compared to non-atopic children without prenatal ETS exposure. Similar results were seen for lower RTI and otitis. This effect was less evident for postnatal ETS.

Conclusion Early atopic status enhances the risk of RTI in children with prenatal ETS exposure. This suggests that host factors modify the association between ETS and RTI.

\section{INTRODUCTION}

Respiratory tract infections (RTI) are among the most common infectious diseases, especially in preschool children, and impose a serious burden on the affected children and their parents. ${ }^{1}$ There is growing awareness that the causes of RTI are multifactorial and that RTI result from interactions between environmental factors and the host. Some of the most evident environmental factors influencing susceptibility to RTI are exposure to environmental tobacco smoke (ETS) and exposure to other children, as encountered at day-care centres, and the presence of siblings. ${ }^{2-5}$ Recognised host factors are, for instance, airway anatomy, immunological factors and atopy. ${ }^{13}$ 6-9 Exposure to ETS is consistently associated with increased risk of RTI in children. ${ }^{10-15}$ However, some children might be more susceptible to the effects of environmental factors on RTI than others. Previously, the association between exposure to other children and RTI in children with and without allergic parents was reported in the

\section{What is already known on this topic}

- Tobacco smoke exposure is associated with increased risk of respiratory tract infections in children.

\section{What this study adds}

- This article shows that early atopic status enhances the risk of respiratory tract infections in children with prenatal tobacco smoke exposure.

- Mothers-to-be of children at high risk of atopy should be particularly discouraged from smoking during pregnancy.

Prevention and Incidence of Asthma and Mite Allergy (PIAMA) birth cohort in the first year of life. ${ }^{16}$ Contacts with other children (day-care attendance or the presence of siblings) increased the risk of RTI to a greater extent in the infants of atopic parents compared with the infants of nonatopic parents.

In addition to the effect of exposure to other children, the effect of exposure to ETS on respiratory infections might also be influenced by host factors such as atopy. We therefore studied whether the association between ETS exposure and RTI is indeed modified by parental allergy or atopic factors in the child itself, as indicated by the presence of elevated $(\geq 0.50 \mathrm{IU} / \mathrm{ml})$ neonatal total $\mathrm{IgE}(\mathrm{t} \operatorname{IgE})$ or clinical symptoms of atopic dermatitis. This was studied in the PIAMA cohort prospectively followed from birth until 4 years of age.

\section{METHODS}

\section{Study population}

Children were participants in the PIAMA birth cohort study. Details of the study design have been published previously. ${ }^{17}$ Recruitment took place in 1996 and 1997. A screening questionnaire was filled in by 10232 pregnant women visiting one of 52 prenatal clinics in the Netherlands. ${ }^{18}$ Based on this screening, 7862 women were invited to participate, and 4146 agreed and gave informed consent. After 
birth the baseline study population consisted of 3963 children. The early phase of the PIAMA study included an intervention, ${ }^{17}$ so both the intervention section and the natural history section of the study were included in our analyses. Questionnaires for parental completion, partly based on the International Study of Asthma and Allergies in Childhood (ISAAC) core questionnaires were sent to the parents during pregnancy, when the child was 3 and 12 months of age, and yearly thereafter up to the age of 4 years. ${ }^{19}$ Complete questionnaire information was available for 2863 children. All allergic mothers $(n=1327)$ and a random sample of non-allergic mothers $(n=663)$ were selected for more extensive investigation, including measurement of neonatal tIgE level in the filter paper blood spot used in routine neonatal screening in the first week of life. Informed consent was obtained from 1755 parents (88\%) but unfortunately, the complex collection and analysis of the blood spot material resulted in random loss of data. Actual measurement of tIgE in the blood was accomplished for 1280 infants (73\%). Data on the studied risk factors and neonatal tgE levels were obtained from 914 infants (71\%). The study was approved by the Institutional Review Board and all parents gave written informed consent.

\section{Outcome variables}

Primary outcome

Information on the frequency of RTI in children 1-4 years of age was collected from annual parental questionnaires using the following question: "How often did your child have serious respiratory tract and/or ear-nose-throat infections, such as $\mathrm{flu}$, infection of the throat, middle ear, or sinuses, bronchitis or pneumonia, during the last 12 months?".

Four answers were possible every year: never, 1-2 times, $3-5$ times and $\geq 6$ times. On the basis of the answers given on the four consecutive annual questionnaires, we defined frequent RTI as $\geq 3$ RTI per year reported on three or four annual questionnaires.

\section{Secondary outcomes}

Information on the frequency of lower RTI (LRTI) and otitis in children 1-4 years of age was collected from annual parental questionnaires using the following questions: "Did a doctor diagnose pneumonia and/or bronchitis in your child in the last 12 months?" and "Did a doctor diagnose infection of the middle ear in your child in the last 12 months?".

On the basis of the answers given on the four consecutive annual questionnaires, we defined LRTI as $\geq 1$ doctor-diagnosed episodes of pneumonia and/or bronchitis during years 1-4, and otitis as $\geq 1$ doctor-diagnosed episode of infection of the middle ear during years $1-4$.

\section{Exposures and confounders}

The following (dichotomous) exposures were defined, based on questionnaires during pregnancy and when the child was 3 and 12 months of age: (1) maternal smoking during pregnancy: any smoking after the 4th week of pregnancy, data collected during pregnancy; (2) postnatal ETS exposure at 3 months: $\geq 1$ cigarette/cigar/pipe per day smoked in the house by the mother, father, others or visitors (visitors: at least 1 day/ week), data collected at 3 months; (3) postnatal ETS exposure at 1 year: combination of exposure to $\geq 1$ cigarette/cigar/pipe per day in the house and/or when the child stayed with family, neighbours, acquaintances, host parents, in a day-care centre or elsewhere, data collected at 1 year.

Previously, it was shown that agreement between reported smoking and air nicotine concentrations within the PIAMA study was good, supporting the validity of the smoking data reported in the questionnaire. ${ }^{20}$

Based on previous literature, potential confounders for susceptibility to RTI were analysed as well, that is, duration of pregnancy, gender, birth weight, body mass index (BMI) (according to standard international age- and gender-specific definitions), breastfeeding (at 12 weeks), day-care attendance (at least $4 \mathrm{~h}$ /week), number of siblings (at 3 months), frequent wheeze ( $\geq 4$ episodes of wheeze in year 1 ), parental allergy (presence of allergy in either one or both parents according to a validated questionnaire) and parental education. ${ }^{18}$

\section{Effect modification by early atopic status}

We studied elevated neonatal tIgE, atopic dermatitis and parental allergy as potential effect modifiers. All were taken as early markers of atopy. ${ }^{21} 22$ tgE was measured by radioallergosorbent tests in plasma obtained from a heel prick blood spot, as described previously. ${ }^{22} 23$ Elevated neonatal tIgE was defined as $\operatorname{tgE} \geq 0.50 \mathrm{IU} / \mathrm{ml}$. Atopic dermatitis (based on the ISAAC questionnaire) was defined at 3 months of age as a history of an itchy rash which came and went on flexural sites (the folds of the elbows or behind the knees), around ears or eyes or in front of the ankles. ${ }^{19}$ Parental allergy was based on the presence of allergy in either one or both parents according to a validated questionnaire. ${ }^{18}$

\section{Statistical analysis}

The associations between pre- and postnatal ETS exposure and early markers of atopy with respiratory infection outcomes at 4 years were analysed by logistic regression analyses. To evaluate potential confounding, we compared at baseline whether the groups with and without exposure differed in relation to the potential confounders. If that was the case, we used the Mantel-Haenszel test to check if the adjusted odds ratio (aOR) differed more than 10\% from the crude OR, which was our cut-off point for actual confounding. aOR with $95 \%$ CI were estimated after selection of the actual confounding factors: frequent wheeze ( $\geq 4$ episodes of wheeze in year 1 ), breastfeeding (at 12 weeks), level of parental education and parental allergy. To investigate the independent effect of pre- and postnatal exposure to ETS, we adjusted the OR of maternal smoking for postnatal ETS exposure and vice versa (after breastfeeding, parental education and parental allergy). Potential effect modification on an additive scale was investigated for elevated neonatal $\mathrm{tIgE}$, atopic dermatitis and parental allergy by stratification of the study population. Interaction on a multiplicative scale by these factors was tested using interaction terms in logistic regression analyses.

All analyses were performed with SPSS statistical software v 15.0 (SPSS, Chicago, Illinois).

\section{RESULTS}

\section{Study population}

Of the 4146 included mothers, 183 (4\%) dropped out before returning the first postnatal questionnaire due to various reasons (eg, stillbirth, language barrier, not interested, moved). Of the 3963 remaining children, complete data on outcomes, exposures and confounders were available in 2863 (72\%). Table 1 gives the characteristics of the study population. The children without complete data were more likely than the children with complete data to have one or two allergic parents ( $44 \%$ and $15 \%$ vs $40 \%$ and $9 \%$ ), to have a mother who smoked during pregnancy ( $25 \%$ vs $15 \%$ ) and to be exposed to 
Table 1 General characteristics of the study population

\begin{tabular}{|c|c|c|c|c|}
\hline & \multicolumn{2}{|c|}{$\begin{array}{l}\text { Children with } \\
\text { complete } \\
\text { questionnaire data } \\
(\mathbf{n}=\mathbf{2 8 6 3 )}\end{array}$} & \multicolumn{2}{|c|}{$\begin{array}{l}\text { Children with } \\
\text { complete } \\
\text { questionnaire } \\
\text { data and } \\
\text { neonatal tlgE } \\
(\mathrm{n}=914)\end{array}$} \\
\hline & $\mathrm{n}$ & $\%$ & n & $\%$ \\
\hline Gender (male) & 1462 & 51 & 465 & 51 \\
\hline $\begin{array}{l}\text { Duration of pregnancy }<37 \\
\text { weeks }\end{array}$ & 135 & 5 & 35 & 4 \\
\hline $\begin{array}{l}\text { Maternal smoking after } \\
\text { 4th week of pregnancy }\end{array}$ & 441 & 15 & 126 & 14 \\
\hline \multicolumn{5}{|l|}{ Birth weight } \\
\hline$<2500 \mathrm{~g}$ & 89 & 3 & 20 & 2 \\
\hline$\geq 2500 \mathrm{~g}$ & 2766 & 97 & 893 & 98 \\
\hline Breastfeeding for $\geq 12$ weeks & 1478 & 52 & 479 & 52 \\
\hline Caesarean section & 243 & 8 & 84 & 9 \\
\hline \multicolumn{5}{|l|}{$\begin{array}{l}\text { Contact with other children } \\
\text { outside home* }\end{array}$} \\
\hline None & 1745 & 61 & 548 & 60 \\
\hline With a few children $(<5)$ & 424 & 15 & 146 & 16 \\
\hline With many children $(\geq 5)$ & 691 & 24 & 219 & 24 \\
\hline \multicolumn{5}{|l|}{ Siblingst } \\
\hline None & 1419 & 50 & 467 & 51 \\
\hline 1 or 2 & 1344 & 47 & 421 & 46 \\
\hline$\geq 3$ & 98 & 3 & 26 & 3 \\
\hline ETS exposure at 3 months & 691 & 24 & 191 & 21 \\
\hline Day-care at age 1 & 692 & 24 & 219 & 24 \\
\hline \multicolumn{5}{|l|}{ Parental allergy $\ddagger$} \\
\hline None & 1442 & 50 & 278 & 30 \\
\hline One parent allergic & 1159 & 40 & 468 & 52 \\
\hline Both parents allergic & 262 & 9 & 168 & 18 \\
\hline \multicolumn{5}{|l|}{ Parental level of education§ } \\
\hline Low & 349 & 12 & 100 & 11 \\
\hline Intermediate & 1796 & 63 & 570 & 62 \\
\hline High & 718 & 25 & 244 & 27 \\
\hline Atopic dermatitis at 3 months & 221 & 8 & 83 & 9 \\
\hline Neonatal tlgE $\geq 0.50 \mathrm{IU} / \mathrm{ml}$ & NA & NA & 83 & 9 \\
\hline Frequent RTI & 120 & 4 & 42 & 5 \\
\hline Otitis & 1398 & 49 & 455 & 50 \\
\hline LRTI & 780 & 27 & 261 & 29 \\
\hline Frequent wheezeף & 196 & 7 & 60 & 7 \\
\hline
\end{tabular}

*At 1 year of age; tat 3 months of age; łaccording to validated questionnaire; §low parental level of education: both parents a maximum of 4 years at highschool; high parental level of education: both parents went to university; intermediate parental level of education: the remaining parents; ๆdefined as $\geq 4$ episodes of wheeze in year 1 .

ETS, environmental tobacco smoke; LRTI, lower respiratory tract infections; RTI. respiratory tract infections; tlgE, total $\lg \mathrm{E}$.

ETS at 1 year (35\% vs $24 \%)$. The characteristics of the children with neonatal tgE data $(n=914)$ were similar to those of the complete population of our study $(n=2863)$, except for parental allergy which was more prevalent in the first group as a results of the original PIAMA study design (at least one allergic parent in $70 \%$ vs $49 \%)^{17}$

\section{Association between RTI, ETS exposure and early atopic status}

The prevalence of frequent RTI ( $\geq 3$ RTI per year reported by the parents in 3 or 4 years) during first 4 years of life was $4 \%$ in our study population. At least one episode of doctordiagnosed LRTI was reported in $27 \%$ and one episode of doctor-diagnosed otitis in $49 \%$ of the children in 4 years. The
Table 2 Association between frequent $\mathrm{RTI}^{*}$ and risk factors $(\mathrm{n}=2863)$

\begin{tabular}{|c|c|c|}
\hline & $\begin{array}{l}\text { Crude ORT } \\
\text { (95\% Cl) }\end{array}$ & aOR $\neq(95 \% \mathrm{Cl})$ \\
\hline $\begin{array}{l}\text { Maternal smoking during } \\
\text { pregnancy }\end{array}$ & 1.64 (1.06 to 2.55$)$ & 1.46 (0.85 to 2.49$)$ \\
\hline ETS exposure at 3 months & $1.32(0.88$ to 1.97$)$ & 0.96 (0.59 to 1.58$)$ \\
\hline ETS exposure at 1 year & 0.99 (0.66 to 1.49$)$ & 1.53 (0.93 to 2.50$)$ \\
\hline Atopic dermatitis at 3 months & 2.21 (1.31 to 3.72 ) & 1.84 (1.07 to 3.17$)$ \\
\hline Elevated neonatal tlgE§ & 1.38 (0.53 to 3.60$)$ & 1.11 (0.41 to 3.01$)$ \\
\hline Parental allergy $\llbracket$ & 1.61 (1.11 to 2.34$)$ & 1.56 (1.06 to 2.29 ) \\
\hline Frequent wheeze ${ }^{* *}$ & 4.65 (2.96 to 7.30$)$ & 4.05 (2.55 to 6.44$)$ \\
\hline Breastfeeding for $<12$ weeks & $1.76(1.21$ to 2.56$)$ & 1.56 (1.06 to 2.31 ) \\
\hline $\begin{array}{l}\text { Low level of parental } \\
\text { educationt } \dagger\end{array}$ & 2.24 (1.31 to 3.82$)$ & 2.06 (1.18 to 3.57$)$ \\
\hline
\end{tabular}

*Frequent RTI: three or more respiratory tract infections per year in 3 or 4 years during the first 4 years of life;

tcrude $\mathrm{OR}$ based on univariate analyses; $¥ \mathrm{aOR}$ : OR adjusted for breastfeeding (at 12 weeks), level of parental education, parental allergy, postnatal ETS exposure (at 3 months) and frequent wheeze if appropriate; §elevated neonatal tlgE: $\operatorname{tg} E \geq 0.50 \mathrm{IU} / \mathrm{ml}$, available for 914 children; flaccording to validated questionnaire; ${ }^{*}$ frequent wheeze: $\geq 4$ episodes of wheeze in year $1_{i}$ t†low parental level of education: both parents a maximum of 4 years at high-school; high parental level of education: both parents went to university; intermediate parental level of education: the remaining parents.

ETS, environmental tobacco smoke; RTI, respiratory tract infections; tlgE, total lgE.

Table 3 Association between prenatal ETS exposure and frequent RTI*: potential effect modification by (A) elevated neonatal tlgE $(n=914)$ and $(B)$ atopic dermatitis $(n=2863)$

\begin{tabular}{|c|c|c|c|c|c|c|}
\hline $\begin{array}{l}\text { Maternal } \\
\text { smoking } \\
\text { during } \\
\text { pregnancy }\end{array}$ & $\begin{array}{l}\text { Elevated } \\
\text { neonatal } \\
\text { tlgE† }\end{array}$ & n & $\begin{array}{l}\text { Crude } \\
\text { OR }\end{array}$ & $95 \% \mathrm{Cl}$ & aOR & $95 \% \mathrm{Cl}$ \\
\hline - & - & 718 & 1 & & 1 & \\
\hline+ & - & 113 & 0.76 & 0.27 to 2.19 & 0.50 & 0.15 to 1.66 \\
\hline- & + & 70 & 0.30 & 0.04 to 2.23 & 0.24 & 0.03 to 1.86 \\
\hline+ & + & 13 & 9.23 & 2.70 to 31.52 & 6.18 & 1.45 to 26.34 \\
\hline \multicolumn{7}{|c|}{$\begin{array}{l}\text { Interaction } p=0.006 \text {. } \\
{ }^{*} \text { Frequent RTI: three or more respiratory tract infections per year in } 3 \text { or } 4 \text { years } \\
\text { during the first } 4 \text { years of life; televated neonatal tlgE: total IgE } \geq 0.50 \mathrm{IU} / \mathrm{ml} \text {; } \\
\text { ‡aOR: OR adjusted for breastfeeding (at } 12 \text { weeks), level of parental education, } \\
\text { parental allergy, postnatal ETS exposure (at } 3 \text { months) and frequent wheeze }(\geq 4 \\
\text { episodes of wheeze) in year } 1 \text {. }\end{array}$} \\
\hline
\end{tabular}

\begin{tabular}{lllllll}
$\begin{array}{l}\text { Maternal } \\
\text { smoking } \\
\text { during } \\
\text { pregnancy }\end{array}$ & $\begin{array}{l}\text { Atopic } \\
\text { dermatitis }\end{array}$ & $\mathbf{n}$ & $\begin{array}{l}\text { Crude } \\
\mathbf{O R}\end{array}$ & $\mathbf{9 5 \%} \mathbf{C l}$ & $\mathbf{a 0 R \S}$ & $\mathbf{9 5 \%} \mathbf{C l}$ \\
\hline- & - & 2225 & 1 & & 1 & \\
+ & - & 417 & 1.49 & 0.92 to 2.42 & 1.39 & 0.78 to 2.47 \\
- & + & 197 & 1.89 & 1.03 to 3.47 & 1.76 & 0.95 to 3.24 \\
+ & + & 24 & 7.06 & 2.57 to 19.37 & 5.69 & 2.01 to 16.04
\end{tabular}

Interaction $p=0.14$.

$\S a 0 R: 0 R$ adjusted for breastfeeding (at 12 weeks), level of parental education, parental allergy, postnatal ETS exposure (at 3 months), frequent wheeze ( $\geq 4$ episodes of wheeze) in year 1 and atopic dermatitis at 3 months. ETS, environmental tobacco smoke; tlgE, total IgE.

primary outcome measure, frequent RTI, was associated with the secondary outcomes LRTI and otitis (OR 6.33 (4.27 to 9.38) and 4.68 (2.95 to 7.41$)$, respectively). Maternal smoking during pregnancy was present in $15 \%$ and postnatal ETS exposure (at age 3 months) in $24 \%$ of the study population. Prenatal ETS 
exposure only without postnatal exposure (at 3 months) was present in 118 children (4\%), whereas postnatal exposure only was present in 368 children (12\%). Elevated neonatal tgE and atopic dermatitis at 3 months was reported in $9 \%$ and $8 \%$ of the study population, respectively.

Frequent RTI, LRTI and otitis were not associated with maternal smoking during pregnancy on its own (aOR 1.46 (0.85 to 2.49), 1.23 (0.97 to 1.56 ) and 1.24 (0.95 to 1.62 ), respectively) (table 2 , results for LRTI and otitis not shown). Neither was postnatal ETS exposure at 3 months or 1 year associated with any of the infection outcomes. A strong association was found for frequent RTI and frequent wheeze in year 1 ( $\mathrm{aOR}$ 4.05 (2.55 to 6.44)) (table 2). Atopic dermatitis at 3 months, parental allergy, breastfeeding for $<12$ weeks and low parental level of education were to a lesser extent associated with increased risk of frequent RTI (table 2). By contrast, elevated neonatal tIgE was not associated with frequent RTI (aOR 1.11 (0.41 to 3.01)).

To study the influence by type of study (intervention or natural history study), we separated the children by type of study. As we found similar results in both groups (data not shown), both groups were combined in further analyses.

\section{Effect modification by early atopic status}

Maternal smoking during pregnancy on its own was overall not statistically significantly associated with increased risk of RTI, but a strong association with RTI was found in children with prenatal ETS exposure and elevated neonatal tgE or atopic dermatitis (table 3). In children with elevated neonatal tgE, maternal smoking during pregnancy was strongly associated with frequent RTI (aOR 6.18 (1.45 to 26.34)) (table 3). The interaction between maternal smoking during pregnancy and elevated neonatal $\mathrm{tIgE}$ in relation to frequent RTI was found to be statistically significant on a multiplicative scale $(p=0.006)$. The effect of prenatal exposure on risk of doctor-diagnosed LRTI and otitis was not increased by the presence of elevated neonatal tgE (results not shown).

The largest effect of atopic dermatitis was seen for frequent RTI (aOR 5.69 (2.01 to 16.04); interaction p=0.14) (table 3). However, the effect of prenatal exposure on risk of doctordiagnosed LRTI (aOR 4.34 (1.90 to 9.92)) and otitis (aOR 2.90 (1.19 to 7.06)) was also increased by the presence of atopic dermatitis (not shown). In children without atopic dermatitis, the associations were not statistically significant (aOR 1.39 (0.78 to 2.47$), 1.26$ (0.96 to 1.66 ) and 1.18 (0.93 to 1.51$)$ ) for frequent RTI, LRTI and otitis, respectively.

Parental allergy did not show significant effect modification (interaction term $p=0.26$, results not shown). Postnatal ETS exposure in relation to frequent RTI did not show effect modification by any of the early markers of atopy (results not shown).

\section{DISCUSSION}

In this large prospective birth cohort study, we found that elevated neonatal tgE, as an early marker of atopic status, enhanced the effect of prenatal ETS exposure on the susceptibility to RTI during the first 4 years of life. This was also true for a clinical marker such as atopic dermatitis. By contrast, postnatal ETS exposure was not obviously associated with increased risk of RTI, independent of early atopic status.

Several studies also showed an association between ETS exposure and RTI. ${ }^{10-15}$
Exposure to tobacco smoke may increase the risk of RTI through suppression or modulation of the immune system, enhancement of bacterial adherence factors, or impairment of the mucociliary apparatus of the respiratory tract. ${ }^{24}$ Previously, eczema has been related to increased infection rate as well. ${ }^{25}$ To our knowledge, we are the first to report that the association between prenatal ETS exposure and frequent RTI is modified by elevated neonatal tIgE or early atopic dermatitis. Furthermore, our results suggest the intriguing possibility of no ETS effect among 'non-atopics'. The increased vulnerability for RTI in children with early markers of atopy exposed to ETS may be explained by subclinical atopic inflammation of the airways which can be present at an early age before clinical respiratory symptoms. ${ }^{26}$ Moreover, adjusting the analyses for the influence of clinical symptoms such as frequent wheeze, as we have done, did not change the results. This shows that elevated neonatal tgE is the actual effect modifier, not symptoms of asthma. Future studies are necessary to elucidate a possible effect of subclinical atopic airway inflammation on the relationship between ETS exposure and RTI in early childhood.

The importance of timing of the exposure to tobacco smoke for effect on RTI that we found has been seen in some previous studies, although others reported conflicting results. ${ }^{10-15}$ 27-30 The methodological characteristics of the studies may to a large extent explain the reported differences in outcome. Studying the independent effect of in utero and postnatal exposure to ETS is difficult because of the strong correlation between the two factors. We tried to overcome this difficulty by adjusting the OR of maternal smoking for postnatal ETS exposure and vice versa and found the strongest effect for prenatal exposure. The absence of associations in the postnatal group may be caused by report bias, for example, if mothers who smoked postnatally were less prone to report smoking. On the other hand, it may be that prenatal exposure is indeed more harmful. ${ }^{1327-29}$ The results of our sensitivity analyses with different cut-offs for postnatal ETS exposure, for example, with a more narrow exposure variable smoking by both parents at age 3 months (7\%), were in agreement with the other results.

The major strengths of our study are the population-based prospective design, and collection of exposure data at several stages before disease manifestation. Moreover, the large sample size allowed us to control for several confounders in studying the association between ETS exposure and RTI and, above all, to study potential effect modification by early atopic status. These interactions are relevant, since frequent RTI have a multifactorial origin and many different factors may contribute.

Some of our findings deserve further discussion. First, outcomes were based on information derived from parental questionnaires. The use of questionnaire information enabled us to study a large group of children for a long period of time but might have resulted in some misclassification. However, we believe that our misclassification is nondifferential since we do not expect that mothers of children with frequent RTI were more prone to report smoking in the questionnaires collected during pregnancy than mothers of children without frequent infections. Therefore, the effect estimate may be underestimated. Second, due to the relatively rare risk factors and primary outcome measure, the numbers are very low in some of the groups. This may explain the lack of statistically significant findings related to ETS exposure. Statistical significance does not necessarily 
imply clinical relevance. If the true difference between two groups is so small that it is clinically irrelevant, a sample size can be found for which this difference is statistically significant. On the other hand, if the difference between two groups is statistically non-significant, it may still be clinically important. Third, it would be informative to use information on exposure levels, instead of exposure 'yes' or 'no' (both for maternal smoking during pregnancy and postnatal ETS). However, small numbers hamper these analyses in our study. Fourth, we used elevated neonatal tgE and atopic dermatitis as early markers of atopy in the child itself. Different results have been reported for the association between elevated neonatal tgE and atopic diseases. However, within the PIAMA cohort, is has been shown that elevated neonatal $\operatorname{tgE}(\geq 0.50 \mathrm{IU} / \mathrm{ml})$ is associated with sensitisation at 1 year. ${ }^{22}$ Moreover, there is disagreement about the definition of atopic dermatitis, but compared with other definitions possible with the available data from the PIAMA study, the present definition seems a fairly good indicator of atopic dermatitis. ${ }^{31}$ Finally, response bias may have occurred if the association between ETS exposure and frequent RTI was different for the children who were included in the analyses and those who were excluded because of missing information, leading to an overestimation of the effect.

Overall, we conclude that elevated neonatal tgE, as an early marker of atopy, seems to enhance the risk of RTI during the first 4 years in children with prenatal ETS exposure. This was also found for the clinical marker of atopy, atopic dermatitis. This suggests that host factors may modify the association between ETS exposure and RTI.

Funding The Prevention and Incidence of Asthma and Mite Allergy study is supported by the Netherlands Organization for Health Research and Development (ZON-MW), the Netherlands Asthma Fund, the National Institute of Public Health and the Environment, and the Ministry of Housing, Urban Planning, and the Environment. Jopje Ruskamp is supported by the Wilhelmina Research Fund of the UMC Utrecht.

\section{Competing interests None.}

Ethics approval The study was approved by the Institutional Review Board.

Provenance and peer review Not commissioned; externally peer reviewed.

Patient consent Parental consent obtained.

\section{REFERENCES}

1. Hak E, Rovers MM, Kuyvenhoven MM, et al. Incidence of GP-diagnosed respiratory tract infections according to age, gender and high-risk co-morbidity: the Second Dutch National Survey of General Practice. Fam Pract 2006:23:291-4.

2. Alho $\mathbf{O P}$, Koivu M, Sorri M, et al. Risk factors for recurrent acute otitis media and respiratory infection in infancy. Int J Pediatr Otorhinolaryngol 1990;19:151-61.

3. Rovers MM, Schilder AG, Zielhuis GA, et al. Otitis media. Lancet 2004;363:465-73.

4. Kamper-Jørgensen M, Wohlfahrt J, Simonsen J, et al. Population-based study of the impact of childcare attendance on hospitalizations for acute respiratory infections. Pediatrics 2006;118:1439-46.

5. Kvaerner KJ, Nafstad P, Jaakkola JJ. Upper respiratory morbidity in preschool children: a cross-sectional study. Arch Otolaryngol Head Neck Surg 2000;126:1201-6.
6. Porro E, Calamita P, Rana I, et al. Atopy and environmental factors in upper respiratory infections: an epidemiological survey on 2304 school children. Int J Pediatr Otorhinolaryngol 1992;24:111-20.

7. Ciprandi G, Tosca MA, Fasce L. Allergic children have more numerous and severe respiratory infections than non-allergic children. Pediatr Allergy Immunol 2006;17:389-91.

8. Karevold G, Kvestad E, Nafstad P, et al. Respiratory infections in schoolchildren: co-morbidity and risk factors. Arch Dis Child 2006;91:391-5.

9. Paunio M, Peltola H, Virtanen $\mathbf{M}$, et al. Acute infections, infection pressure, and atopy. Clin Exp Allergy 2006;36:634-9.

10. Strachan DP, Cook DG. Health effects of passive smoking. 4. Parental smoking, middle ear disease and adenotonsillectomy in children. Thorax 1998;53:50-6.

11. Peat JK, Keena V, Harakeh Z, et al. Parental smoking and respiratory tract infections in children. Paediatr Respir Rev 2001;2:207-13.

12. DiFranza JR, Aligne CA, Weitzman M. Prenatal and postnatal environmenta tobacco smoke exposure and children's health. Pediatrics 2004;113:1007-15

13. Håberg SE, Stigum H, Nystad W, et al. Effects of pre- and postnatal exposure to parental smoking on early childhood respiratory health. Am J Epidemiol 2007;166:679-86.

14. Koch A, Mølbak K, Homøe P, et al. Risk factors for acute respiratory tract infections in young Greenlandic children. Am J Epidemio/ 2003;158:374-84

15. Strachan DP, Cook DG. Health effects of passive smoking. 1. Parental smoking and lower respiratory illness in infancy and early childhood. Thorax 1997;52:905-14.

16. Koopman LP, Smit HA, Heijnen ML, et al. Respiratory infections in infants: interaction of parental allergy, child care, and siblings-The PIAMA study. Pediatrics 2001;108:943-8.

17. Brunekreef B, Smit J, de Jongste J, et al. The prevention and incidence of asthma and mite allergy (PIAMA) birth cohort study: design and first results. Pediatr Allergy Immunol 2002;13 Suppl 15:55-60.

18. Lakwijk N, Van Strien RT, Doekes G, et al. Validation of a screening questionnaire for atopy with serum IgE tests in a population of pregnant Dutch women. Clin Exp Allergy 1998;28:454-8.

19. Asher MI, Keil U, Anderson HR, et al. International Study of Asthma and Allergies in Childhood (ISAAC): rationale and methods. Eur Respir J 1995;8:483-91.

20. Brunekreef $\mathbf{B}$, Leaderer BP, van Strien $\mathrm{R}$, et al. Using nicotine measurements and parental reports to assess indoor air: the PIAMA birth cohort study. Prevention and Incidence of Asthma and Mite Allergy. Epidemiology 2000;11:350-2.

21. Spergel JM, Paller AS. Atopic dermatitis and the atopic march. J Allergy Clin Immunol 2003;112:S118-27.

22. Kerkhof M, Wijga A, Smit HA, et al.; PIAMA Study Group. The effect of prenatal exposure on total lgE at birth and sensitization at twelve months and four years of age: The PIAMA study. Pediatr Allergy Immunol 2005;16:10-18.

23. Stapel So, Eysink PE, Vrieze J, et al. IgE testing in capillary blood. Pediatr Allergy Immunol 2004;15:230-3.

24. Kum-Nji P, Meloy L, Herrod HG. Environmental tobacco smoke exposure: prevalence and mechanisms of causation of infections in children. Pediatrics 2006;117:1745-54

25. Hughes AM, Crouch S, Lightfoot T, et al. Eczema, birth order, and infection. Am J Epidemiol 2008;167:1182-7.

26. Pohunek P, Warner J0, Turzíková J, et al. Markers of eosinophilic inflammation and tissue re-modelling in children before clinically diagnosed bronchial asthma. Pediatr Allergy Immunol 2005;16:43-51.

27. Jaakkola JJ, Kosheleva AA, Katsnelson BA, et al. Prenatal and postnatal tobacco smoke exposure and respiratory health in Russian children. Respir Res 2006;7:48.

28. Taylor B, Wadsworth J. Maternal smoking during pregnancy and lower respiratory tract illness in early life. Arch Dis Child 1987;62:786-91.

29. Wright AL, Holberg C, Martinez FD, et al. Relationship of parental smoking to wheezing and nonwheezing lower respiratory tract illnesses in infancy. Group Health Medical Associates. J Pediatr 1991;118:207-14.

30. Stein RT, Holberg CJ, Sherrill D, et al. Influence of parental smoking on respiratory symptoms during the first decade of life: the Tucson Children's Respiratory Study. Am J Epidemiol 1999;149:1030-7.

31. Brenninkmeijer EE, Schram ME, Leeflang MM, et al. Diagnostic criteria for atopic dermatitis: a systematic review. Br J Dermatol 2008;158:754-65. 